\title{
Impact of Subsidies on Technical Efficiency of Meat Processing Companies
}

Tamara Rudinskaya, Zdeňka Náglová

Institute of Agricultural Economics and Information, Prague, Czech Republic

\begin{abstract}
The paper deals with the technical efficiency analysis of meat processors in the Czech Republic and evaluates an impact of subsidies on companies' technical efficiency. Albertina database which collects accounting data of the Czech meat processors was used for the empirical analysis for the programming period 2007-2013. Subsidies data was collected from the public register of recipients of the Ministry of Agriculture of the Czech Republic. In total, 207 meat processors were analysed. The methodological approach taken in this study is based on translogarithmic production function and Stochastic Frontier Analysis. True Random Effects model, and Battese and Coelli model were used to evaluate the impact of subsidies on technical efficiency. The results of both used methods indicate positive impact of subsidies on meat processors technical efficiency. Material input displays the highest elasticity; the lowest elasticity belongs to production factor Capital. Technical change has a positive impact on production.
\end{abstract}

\section{Keywords}

Stochastic Frontier Analysis, technical efficiency, meat processors, subsidies, investments.

Rudinskaya, T. and Náglová, Z. (2018) "Impact of Subsidies on Technical Efficiency of Meat Processing Companies", AGRIS on-line Papers in Economics and Informatics, Vol. 10, No. 1, pp. 61-70. ISSN 1804-1930. DOI 10.7160/aol.2018.100106.

\section{Introduction}

The meat industry is one of the main branches of the Czech food industry together with the bakery and milk industry. Meat industry significantly contributes to the total food industry sales (i.e. $23.2 \%$ in 2016), to the number of employees (24.4\%), and to the number of enterprises $(25.1 \%)$. From the long-term perspective, low wages in the branch are observed. Workers are remunerated below the average wages that are common for CZ-NACE 10 (Food processing industry). There is also a long-time decline in the number of employees (Ministry of Agriculture, 2017). With regard to this unfavorable branch situation, the meat industry was chosen to analyse whether the subsidies contribute to technical efficiency growth. The subsidies in food processing (especially Rural Development Program (RDP)) are expected to contribute to the higher business performance, as stated in the definition of the measure.

Several studies have empirically investigated the effect of subsidies on technical efficiency in agriculture. Piesse and Thirtle (2000) showed that inefficiency, among other factors, can be explained by subsidies. Other negative effects of subsidies on technical efficiency were found for example by Karagiannis and Sarris (2005), Hadley (2006), Zhu and Oude Lansink (2008).

Čechura (2009) and Trnková et al. (2012) dealt with the relationship between subsidies and their impact on farms' efficiency in the Czech Republic. These authors found out rather their negative impact. On the other hand, Pechrová and Vlašicová (2013) proved positive impact of subsidies on technical efficiency.

There are numerous studies analysing the impact of subsidies in the agricultural sector, some of them are listed above. Despite this, little research has been done about the food processing industry (Beckeman and Skjolkebrand, 2007). Innovations and investments are an important instrument of the food industry competitiveness and they are the main instrument of industrial policy (Menrad, 2004; Skuras et al., 2006). Subsidies, being a source of innovation, influence the growth of a firm, and some studies say that no firm can survive without at least some innovation (Geroski et al., 1997; Coad and Rao, 2008). According to Bernini and Pellegrini (2011) subsidies are targeted at influencing the allocation of investments 
to increase competitiveness, sustainable growth and create new workplaces.

According to Mroczek (2013), the last decade has been the period of intense development of the Polish food industry. There has been a significant recovery in investments and an increase in the value of fixed assets of food business enterprises (generally evaluated on the level of whole food processing industry). Investments are active elements of businesses (machinery and equipment), that have significantly improved the performance of food industry.

Skuras et al. (2006) dealt with the effect of subsidies on technical efficiency in Greek food and beverage industry. Subsidies are the main instrument of the industrial and regional policy of developed countries around the world. The results of their research question the positive effect of subsidies on productivity. Bernstein and Mamuneas (2008) investigated the impact of investment in food processing and found, that these investments positively contributed to total factor productivity (TFP) growth. Some other studies indicated also a positive impact on firms' performance, for example Cerqua and Pellegrini (2014), and Geroski (2005). The negative impact was proved by Wynarczyk and Thwaites (1997), Harris and Trainor (2005). Minviel and Latruffe (2017) used meta-analysis approach and found that farm's technical efficiency is commonly negatively influenced by subsidies.

In the Czech environment, the RDP (Rural Development Program) analysis has been provided. Impacts of the measure I. 1. 3. 1 "Adding value to agricultural and food industries to the food business economy" by Mezera et al. (2014) were evaluated. Their results suggest that the aid has a positive impact on financial stability and labor productivity.

The methods used to analyze the impact of subsidies on the food industry business economy is usually based on the contrafactual analysis (Mezera and Špička, 2013). Mezera et al. (2014) in their research used online surveys and interviews. For the analysis of subsidies impact on meat industry economy, fixed effect model was applied (Špička et al., 2017). Evaluation of the technical efficiency of processing companies in the Czech Republic and the Slovak Republic was conducted by Čechura and Malá (2014), Čechura and Hockmann (2010), Čechura and Hockmann (2011), Daňková and Bosáková (2005). However, these studies do not investigate the impact of subsidies on firm's technical efficiency.
Other methods, including production function approach and TFP (Total Factor Productivity) growth calculation, were used by Bergström (2000) to evaluate the impact of subsidies on the productivity of manufacturing industry in Sweden, and by Skuras (2006) for Greek food and beverage manufacturing industry. Bernini and Pellegrini (2011) applied Difference-InDifference Matching (MDID) estimator to evaluate the impact of aids.

The studies, dealing with the analysis of subsidies effect on firm efficiency, are mostly based on two approaches. The first approach considers the subsidy as a conventional input along with labor, land, and capital, and assumes that subsidies directly affect the productivity of firms. This approach has some drawbacks: while traditional inputs are necessary for the production, subsidies are not a necessary production factor and by themselves cannot generate any output, while traditional inputs can (Kumbhakar and Lien, 2010). Hence, this approach is inconsistent with the economic theory.

The second approach uses SFA and assumes that subsidies affect productivity through the mean of technical inefficiency. This approach does not treat subsidies as a traditional input, and therefore escapes criticism of the previous approach. The common argument proposed for the effect of subsidies on technical efficiency is that subsidies discourage farmer from applying more effort into their production activities than in the absence of subsidies, and hence reduce productivity (Kumbhakar and Lien, 2010).

The aim of this article is to evaluate the impact of subsidies of food processing firms on their technical efficiency using Stochastic Frontier Analysis (SFA), True Random Effects model (TRE) (Greene 2005), and Battese and Coelli model (1995). The period 2007-2013 was used to evaluate the total effects of subsidies on technical efficiency in the last programming period. The research questions to be addressed are:

(1) What is the average level of technical efficiency of Czech meat processing companies?

(2) Do subsidies have a positive impact on technical efficiency?

(3) Are there any differences between the results of used methods?

(4) How the technical efficiency of Czech meat processor develops in time?

The paper is structured as follows: the Materials and methods section represent the estimation 
strategy and describes the data set; the Results and discussion section presents the results of production function estimation and compares the obtained results with previous studies, the Conclusion section contains concluding remarks.

\section{Materials and methods}

This chapter specifies the data and used methods, and shortly introduces the data characteristics (Table 1 and Table 2). In this paper, two approaches are used. First, the "True" random effects model, and second, the Battese and Coelli model.

\section{Data input}

The panel data set was collected from the Albertina database. The analysis uses information from the final accounts of companies whose main activity is meat processing (divided according to CZ-NACE, it means branch CZ-NACE 10.1 Processing and preserving of meat and production of meat products) in the period from 2007 till 2013. The time period was used with respect to programming period of Rural Development Programme (RDP). After the cleaning process (checking the correctness of branch of enterprises, removing companies with missing observations and negative values of the variables), the unbalanced panel data set contains 1418 observations of 207 meat processing companies of the Czech Republic. These businesses were divided into size groups according to a number of employees. Three groups were defined (small, medium and large). Small enterprises employ 0-49 employees, medium 49-249 employees and large more than 250 . Total 128 small businesses,
61 medium-sized and 18 large companies were analysed.

Food industry businesses have a possibility to draw the finance from RDP. For the previous programming period 2007-2013, it was the measure I. 1. 3 Adding value to agricultural and food products. The aid is aimed at firms' investment and innovation activity. Information about subsidies drawing was obtained from the Ministry of Agriculture of the Czech Republic, Register of subsidies recipients, which is commonly available. The division of subsidies recipients is shown in table 1.

The following variables were used in the analysis: Output, Labour, Capital, Material input (Material and Energy), and Subsidies. The output is represented by the total sales of goods, products, and services of the food processing company. To avoid price changes, Output was deflated by the price index of food processing companies according to the branch. The Labour input is used in the form of total personnel costs per company, divided by the average annual wage. The Capital variable is represented by the value of tangible assets. Material input is total costs of material and energy consumption per company. Capital and Material were deflated by the price index of the industrial sector. Output, Capital, and Material input variables are measured in thousand CZK, Labour variable is a coefficient.

\section{Stochastic Frontier Analysis (SFA)}

Following Farrell (1957), many different methods have been considered for the estimation of efficiency. Two widely used approaches are the Data Envelopment Analysis (DEA), which is nonparametric and deterministic, and the Stochastic

\begin{tabular}{|l|c|c|c|c|}
\hline Farm size & Number of firms & $\begin{array}{c}\text { Mean } \\
\text { (thous. CZK) }\end{array}$ & $\begin{array}{c}\text { Std.dev } \\
\text { (thous. CZK) }\end{array}$ & $\begin{array}{c}\text { Total sum of subsidies } \\
\text { (thous. CZK) }\end{array}$ \\
\hline Small $(<50$ workers) & 32 & 272.03 & 1922.82 & 235307 \\
\hline Medium (50-250) & 37 & 724.69 & 3634.12 & 309444 \\
\hline Large $(>250)$ & 11 & 1869.99 & 6983.45 & 235619 \\
\hline
\end{tabular}

Source: own processing

Table 1: Division of subsidies recipients depending on farm size.

\begin{tabular}{|l|c|c|c|c|}
\hline Variable & $\begin{array}{c}\text { Mean } \\
\text { (thous. CZK) }\end{array}$ & $\begin{array}{c}\text { Std. deviation } \\
\text { (thous. CZK) }\end{array}$ & $\begin{array}{c}\text { Min } \\
\text { (thous. CZK) }\end{array}$ & $\begin{array}{c}\text { Max } \\
\text { (thous. CZK) }\end{array}$ \\
\hline Output & 222483 & 510863.3 & 525.8 & 5060008 \\
\hline Capital & 84427.34 & 254630.1 & 123.5 & 3731411 \\
\hline Labour & 21024.62 & 44717.43 & 42.1 & 480140 \\
\hline Material & 205519.6 & 448403.7 & 87.2 & 4922032 \\
\hline
\end{tabular}

Source: own processing

Table 2: Characteristics of data set (average per enterprise). 
Frontier Analysis (SFA), which is, on the contrary, parametric.

Differences between these approaches can be considered according to the assumptions and techniques used to construct an efficient frontier. On the one hand, parametric methods estimate the frontier using statistical methods. On the other hand, nonparametric methods rely on linear programming to calculate the values of the efficient frontier.

Parametric methods impose an explicit functional form for the frontier and require the distributional assumption of the inefficiency term. Nonparametric methods, in contrast, impose neither assumptions about the functional form of the frontier nor any distributional assumptions about inefficiency. Estimation of the frontier, in turn, allows for random noise in the analysis. Moreover, it allows hypotheses testing. Therefore, many authors have concluded that parametric methods, such as SFA, is more suitable for efficiency analysis in agriculture, where measurement errors and differences in climate conditions take place.

To study the determinants of technical efficiency we used the SFA methodology developed by Aigner et al. (1977). Stochastic frontier models allow analysing technical inefficiency in the framework of production functions. The SFA method is based on an econometric (i.e., parametric) specification of a production frontier. Using a generalized production function and cross-sectional data, this method can be depicted as follows:

$$
y_{i}=f\left(x_{i j} ; \beta\right) \cdot \exp \left(\varepsilon_{i}\right)
$$

where $y$ represents output, $x$ is a vector of inputs, $\beta$ is a vector of unknown parameters, and $\varepsilon$ is the error term. The subscripts $i$ and $j$ denote the firm and inputs, respectively.

In this specific formulation, the error term is farm specific and is composed of two independent components, $\varepsilon_{i}=v_{i}-u_{i}$. The first element, $v_{i}$ is a random variable reflecting noise and other stochastic shocks entering the definition of the frontier, such as weather, luck, strikes, and so on. This term is assumed to be an independent and identically distributed normal random variable with zero mean and constant variance iid $\left[\boldsymbol{N} \sim\left(\mathbf{0}, \boldsymbol{\sigma}_{v}^{2}\right)\right]$.

The second component, $u_{i}$, captures technical inefficiency relative to the stochastic frontier. The inefficiency term $u_{i}$ is nonnegative and it is assumed to follow a half-normal distribution (Kumbhakar and Lovell 2000).
An index for TE can be defined as the ratio of the observed output $(y)$ and maximum feasible output $\left(y^{*}\right)$ :

$T E_{i}=\frac{y_{i}}{y_{i}^{*}}=\frac{f\left(x_{i j} ; \beta\right) \cdot \exp \left(v_{i}-u_{i}\right)}{f\left(x_{i j} ; \beta\right) \cdot \exp \left(v_{i}\right)}=\exp \left(-u_{i}\right)$

Because $y \leq y^{*}$, the TE index is bounded between 0 and 1; TE (technical efficiency) achieves its upper bound when a firm is producing the maximum output feasible level (i.e., $y=y^{*}$ ), given the input quantities. Jondrow et al. (1982) demonstrated that farm-level TE for half-normal distribution of inefficiency term can be calculated from the error term $\varepsilon i$ as the expected value of $-u_{i}$ conditional on $\varepsilon_{i}$, which is given by

$$
E\left[u_{i} \mid \varepsilon_{i}\right]=\frac{\sigma_{u} \sigma_{v}}{\sigma}\left[\frac{\phi\left(\varepsilon_{i} \lambda / \sigma\right)}{1-\Phi\left(\varepsilon_{i} \lambda / \sigma\right)}-\frac{\varepsilon_{i} \lambda}{\sigma}\right]
$$

where $\sigma^{2}=\sigma_{u}{ }^{2}+\sigma_{v}^{2}, \lambda=\sigma_{u} \sigma_{v} \phi(\cdot)$ represent the standard normal density and $\Phi(\cdot)$ the standard normal cumulative density functions.

In the case of exponential distribution of inefficiency farm-level TE is calculated in the form

$$
E\left[u_{i} \mid \varepsilon_{i}\right]=\widetilde{\mu}_{\boldsymbol{\imath}}+\sigma_{v}\left[\frac{\phi\left(-\widetilde{\mu_{\imath}} / \sigma_{v}\right)}{1-\Phi\left(\widetilde{\left.\mu_{\imath} / \sigma_{v}\right)}\right.}\right]
$$

where $\tilde{\mathrm{u}}=-\varepsilon-\sigma_{v}^{2} / \sigma_{u}$

Thus, the TE measure for each firm is equal to $T E_{i}=\exp \left(-E\left[u_{i}\left|\varepsilon_{i}\right|\right)\right.$

\section{"True" random effects model (TRE)}

In the fixed-effects model, it is assumed that the inefficiency term is fixed and the correlation with regressors is allowed. Unlike fixed effects model the opposite situation is considered, in which the $u_{i}$ are randomly distributed with constant mean and variance, but are assumed to be uncorrelated with the regressors and the $v_{i t}$. The random effects specification assumes that the firm specific inefficiency is the same every year, i.e. the inefficiency term is time invariant. In these propositions, the model absorbs all unmeasured heterogeneity in $u_{i}$.

Greene (2005) argued that the random effects model with the proposed extensions has three significant weaknesses. The first is its implicit assumption that the effects are not correlated with the included variables. The second problem with the random effects is its hypothesis that the inefficiency is the same in every period. For a long time series data, this is likely to be an undesirable assumption. The third shortcoming of this model is that in this model $u_{i}$ carries both the inefficiency 
and, in addition, any time invariant firm specific heterogeneity. To avoid the former limitations Greene (2005) proposed "True" random effects model that is as follows:

$y_{i t}=\alpha+\beta^{\prime} x_{i t}+w_{i}+v_{i t}-u_{i t}$

where $w_{i}$ is the random firm specific effect and $v_{i t}$ and $u_{i t}$ are the symmetric and one sided components.

Since heterogeneity between food processing firms was proved by many studies (see Čechura and Hockmann, 2017; Rudinskaya, 2017) TRE model was chosen as an appropriate tool.

\section{Battese and Coelli model (1995)}

Beside the TRE model, the empirical part of the paper is based on Battese and Coelli (1995) model (technical inefficiency effects model). Battese a Coelli (1995) incorporate vector of explanatory variables $z_{i t}{ }^{\prime}$, which influence technical efficiency of firm $i$ at time $t$

$u_{i t}=z_{i t}{ }^{\prime} \delta+w_{i t}$

where $\delta$ is a vector of unknown parameters, wit is a random term defined by truncated-normal distribution.

According to this model TEit $=\exp \left(-u_{i t}\right)$ $=\exp \left\{-z_{i t} \delta-w_{i t}\right\}$.

Battese and Coelli (1995) model was chosen to analyse the effect of subsidies on technical inefficiency mean.

\section{Results and discussion}

The empirical analysis is based on the estimation of translogarithmic production function in which both the output and inputs are expressed in logarithmic form and normalised by their arithmetic means. The inefficiency term is assumed to have an exponential distribution.
The three factor translogarithmic production function was estimated in the form:

$$
\begin{aligned}
\ln y_{i t} & =\beta_{0}+\sum_{j=1}^{J} \beta_{j} \ln x_{j i t}+\beta_{t} t \\
& +\frac{1}{2} \sum_{j=1}^{J} \sum_{k=1}^{K} \beta_{j k} \ln x_{j i t} \ln x_{k i t}+\frac{1}{2} \beta_{t t} t^{2} \\
& +\sum_{j=1}^{J} \beta_{j t} \ln x_{j i t} t+\varepsilon_{i t}
\end{aligned}
$$

where $y$ is output, $x$ with subscript $j$ refers to a certain production factor, subscripts $i$, with $i=1,2, \ldots, N$, and $t$, with $t=1, \ldots, T$, refer to a certain producer and time (year), respectively.

The first-order estimated parameters Capital (C), Labour (L), Material input (M) are significant under z-test at $1 \%$ level of significance (Table 3 ). It means, that these variables have a significant impact on total production. Signs of the coefficients are positive that is consistent with economic theory (the assumption of monotonicity is fulfilled). The curvature condition of quasi-concavity in inputs (diminishing marginal productivity for each input) is achieved in the case of all production factors. Since the values of production factors were normalised by their arithmetic means after logarithmic transformation, in translogarithmic model these coefficients represent elasticities, that is possible percentage change in aggregate output because of one percent change in input. All production elasticities are positive; the highest elasticity displays Material input (0.82783). If the Material input change by one percent, the production will change by $0.82783 \%$. The lowest elasticity belongs to production factor Capital (0.02234). If Capital change by one percent, the production will change by $0.02234 \%$. Technical change has a positive

\begin{tabular}{|l|c|c|l|c|c|}
\hline Variable & Coefficient & p-value & Variable & Coefficient & p-value \\
\hline Const. & 0.43889 & 0.000 & CL & -0.00219 & 0.000 \\
\hline C & 0.02234 & 0.000 & CM & 0.01741 & 0.000 \\
\hline L & 0.12658 & 0.000 & LM & -0.00809 & 0.000 \\
\hline M & 0.82783 & 0.000 & CT & 0.00084 & 0.000 \\
\hline T & 0.00416 & 0.000 & LT & 0.00019 & 0.000 \\
\hline CC & 0.00337 & 0.000 & MT & -0.00721 & 0.000 \\
\hline LL & 0.01445 & 0.000 & Usigma Subsidies & -0.00006 & 0.002 \\
\hline MM & 0.00049 & 0.002 & Const. & -1.82686 & 0.000 \\
\hline TT & 0.00863 & 0.000 & Vsigma Const. & -21.38963 & 0.001 \\
\hline
\end{tabular}

Source: own processing

Table 3: The estimation results of TRE model with subsidies variable. 
impact on production (the variable Time $(T)$ is positive and significant at $1 \%$ level of significance). Moreover, the impact of technical change accelerated over time $(\beta \mathrm{TT}>0)$. It is characterised by Labour- and Capital intensive, and Materialsaving behaviour. The sector is characterised by slightly diminishing returns to scale. Subsidies variable has impact on the variance of technical inefficiency.

Nivievskyi and von Cramon-Taubadel (2008) in their research found that labour intensity has a negative impact on farm competitiveness.

The parameters of the Battese and Coelli model are statistically significant at $1 \%$ level of significance (Table 4). The slopes of the coefficients are positive, that is consistent with economic theory. The highest elasticity belongs to the production factor Material $(0.82233)$. The other factors have a lower impact on production (0.14016 for Labour and 0.04457 for Capital). Estimated parameters of production factors satisfy the curvature assumption of quasiconcavity in inputs. The parameter $\lambda$ is more than one indicates that the variation in efficiency component is more significant than the variation in statistical noise. Technical change is characterised by Labour- intensive, and Capital- and Materialsaving behaviour. The sector is characterised by constant returns to scale. The previous model (TRE) estimated diminishing returns to scale, but the difference between two estimated values is rather insignificant. Subsidies variable positively influence the technical efficiency mean. Both of used methods indicated a significant impact of subsidies on technical efficiency. Moreover, Battese a Coelli model proved that the impact is positive.

Bernini and Pellegrini (2011) show higher growth in output, employment, and fixed assets in subsidized firms, but a lower increase in total factor productivity than in unsubsidized manufacturing firms in Sweden. The negative effect of subsidies on efficiency and productivity in food industry sector was found by Harris and Trainor (2005), Harris and Trainor (2005), and Skuras (2006). In this paper, as well as in research of Cerqua and Pellegrini (2014), and Bernstein and Mamuneas (2008), a positive effect was estimated.

By empirical analysis was proved, that subsidies have a positive impact on technical efficiency. Moreover, the development of technical efficiency has increasing trend from 2007 to 2010 (Graph 1). We can say, that inputs were used very efficiently and the average technical efficiency has increased. However, since 2010 the technical efficiency has decreased. The explanation of the reasons is questionable. It can be caused, on the one hand, by changing the structure of the database itself. On the other hand, analysed subsidies (considering their investment and innovation behaviour) are the part of the inputs, i.e. the Capital variable. By the certain point of the subsidies reception, the efficiency of subsidies applying can decrease, that could result in lower technical efficiency.

These results are consistent with Bergström (2000) who found that subsidisation is positively correlated with the growth of value added, and productivity of the subsidised firms appears to increase in the first year. After the first year, however, the more subsidies a firm has received, the worse productivity growths development was observed. Subsidies can lead to lower firms' productivity because they give firms an incentive to change the mix of capital and labour and it can lead to inefficiencies. Moreover, the subsidised firms might be over-invested in the capital.

Other cause can be repeated aids received by the same firm. There were some firms, that received subsidies repeatedly, so the application of new investment did not reach adequate outputs.

\begin{tabular}{|l|c|c|l|c|c|}
\hline Variable & Coefficient & p-value & Variable & Coefficient & p-value \\
\hline Const. & 0.90462 & 0.000 & CL & -0.00366 & 0.006 \\
\hline C & 0.04457 & 0.000 & CM & 0.04082 & 0.000 \\
\hline L & 0.14016 & 0.000 & LM & -0.01814 & 0.000 \\
\hline M & 0.82233 & 0.000 & CT & -0.00919 & 0.061 \\
\hline T & 0.02703 & 0.001 & LT & 0.00360 & 0.003 \\
\hline CC & 0.00241 & 0.063 & MT & -0.01593 & 0.005 \\
\hline LL & 0.01708 & 0.000 & Mu & & \\
\hline MM & 0.01643 & 0.031 & Subsidies & -155.752 & 0.000 \\
\hline TT & 0.00374 & 0.537 & lambda & 80.01371 & 0.000 \\
\hline
\end{tabular}

Source: own processing

Table 4: The estimation results of Battese and Coelli model (1995) with subsidies. 


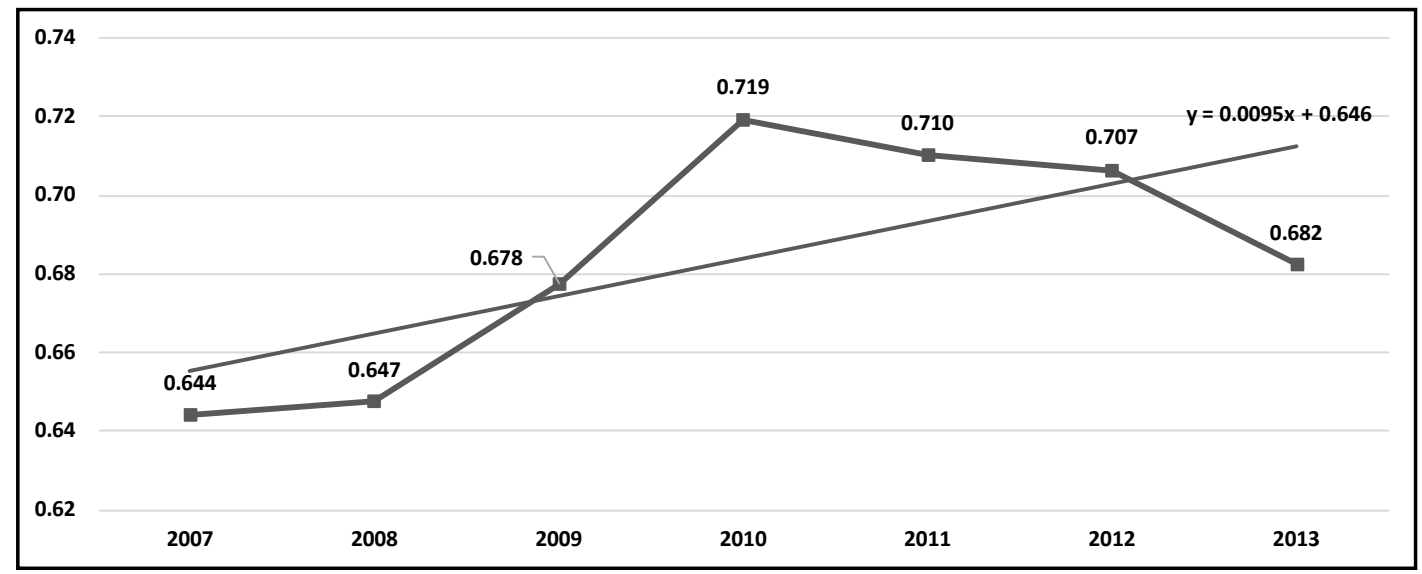

Source: own processing

Graph 1: TE development.

\begin{tabular}{|l|l|l|l|l|l|}
\hline Farm size & Number of firms & Mean & Std. dev & Max value & Coef. of variation \\
\hline Small $(<50$ workers) & 128 & 0.6707 & 0.2701 & 0.9882 & $40.3 \%$ \\
\hline Medium $(50-250)$ & 61 & 0.7021 & 0.2307 & 0.9379 & $32.9 \%$ \\
\hline Large $(>250)$ & 18 & 0.7333 & 0.2313 & 0.9526 & $31.5 \%$ \\
\hline
\end{tabular}

Source: own processing

Table 5: Estimated TE depending on farm size.

Table 5 shows estimated technical efficiency depending on farm size. The most efficient are large meat processors with more than 250 employees. Their operation expects a high degree of investments and innovations with automated processes that can help them to reach higher labour productivity and effective use of inputs. Least efficient are small processors. Small firms usually do not invest in new technologies (as shown in table 1, the average subsidy was 272 thousand CZK). They focus on manual manufacture and production of a specialized range of good, where is not possible to use machines and other equipment to such an extent. The coefficient of variation indicates relatively high variation of technical efficiency level in the group of small farms. As the size of firms grows, their estimated technical efficiency level approaches to average.

\section{Conclusion}

Production elasticities estimated for Capital, Labour, and Variable input are 0.02234, 0.12658 and 0.82783 in case of TRE model and $0.04457,0.14016$ and 0.82233 in case of Battese and Coelli model, that is consistent with the results of previous studies (Čechura and Hockmann, 2010; Rudinskaya, 2017). Both models estimated almost similar production elasticity. The higher elasticity of variable input can be explained by the fact that meat processing industry is a sector in which agricultural raw material plays the central role in the production processes. For the average firm in the full sample, there is a constant or slightly diminishing economies of scale. It suggests that the impact of production expansion on a production level will be rather small. Technical progress is characterized by Labour- and Capital intensive, and Material-saving behaviour, that is partially in context with the expectation of Čechura and Hockmann (2010) for this period. Authors expected Capital-using and Labour-saving technical change.

Subsidies on investments, that anticipate the modernization of food industry production, positively contribute to the growth of technical efficiency. According to recent surveys (see Boudný and Janotová 2015), higher labour productivity in Western EU countries is due to a higher level of organization, modernization, and automation which is associated with a relatively high investment intensity. In the Czech Republic, labour productivity is relatively low compared to the other Member States. In this context, subsidies on the modernization of food industry production are an important source of growth in technical efficiency.

Development of technical efficiency had increasing trend until the year 2010, after that period, however, technical efficiency in meat processing sector decreased. The recipients of the highest amount 
of subsidies are mostly large food processing companies, which represent a lower number of firms and higher technical efficiency.

These findings are the important message for policy makers with respect to the setting of CAP subsidies for the next programming period. Many studies evidenced that subsidies supporting investment and innovation activity, positively influence overall competitiveness in food processing sector by increasing their technical efficiency. However, more attention must be paid to small entities and efficient subsidies facilities utilization.

\section{Acknowledgements}

The paper was supported by internal research project of the Institute of Agricultural Economics and Information "MEAT - Strategy analysis of the meat processing industry in the Czech Republic" (1294/2017).

Corresponding authors:

Tamara Rudinskaya, Ph.D.

Institute of Agricultural Economics and Information, Mánesova 1453/75, 120 00, Prague 2, Czech Republic E-mail: rudinskaya.tamara@uzei.cz

Ing. Zdeňka Náglová, Ph.D.

Institute of Agricultural Economics and Information, Mánesova 1453/75, 120 00, Prague 2, Czech Republic E-mail:naglova.zdenka@uzei.cz

\section{References}

[1] Aigner, D., Lovell, C. A. K. and Schmidt, P. (1977) "Formulation and Estimation of Stochastic Frontier Production Function Models", Journal of Econometrics, Vol. 6, No. 1, pp. 1-37. ISSN 0304-4076. DOI 10.1016/0304-4076(77)90052-5.

[2] Battese, G. and Coelli, T. (1992) "Frontier production functions, technical efficiency and panel data with application to paddy fanners in India", Journal of Productivity Analysis, Vol. 3, No. 1, pp. 153-169. ISSN 1573-0441. DOI 10.1007/BF00158774.

[3] Battese, G. and Coelli, T. (1995) "A model for technical inefficiency effects in a stochastic frontier production function for panel data", Empirical Economics, Vol. 20, No. 2, pp. 325-332. ISSN 1435-8921. DOI 10.1007/BF01205442.

[4] Beckeman, M. and Skjolkebrand, C. (2007) "Cluster/networks promote food innovations", Journal of Food Engineering, Vol. 79, No. 4, pp. 418-1425. ISSN 0260-8774. DOI 10.1016/j.jfoodeng.2006.04.024.

[5] Bergström, F. (2000) "Capital subsidies and the performance of firms", Small Business Economics, Vol. 14, No. 3, pp. 183-193. ISSN 1573-0913. DOI 10.1023/A:1008133217594.

[6] Bernini, C. and Pellegrini G. (2011) "How are growth and productivity in private firms affected by public subsidy? Evidence from a regional Policy", Regional Science and Urban Economics, Vol. 41, No. 3, pp. 253-265. ISSN 0166-0462. DOI 10.1016/j.regsciurbeco.2011.01.005.

[7] Bernstein, J. I. and Mamuneas, T. P. (2008) "Public infrastructure, input efficiency and productivity growth in the Canadian food processing industry", Journal of Productivity Analysis, Vol. 29, pp. 1-13. ISSN 1573-0441. DOI 10.1007/s11123-007-0063-5.

[8] Boudný, J. and Janotová, B. (2015) "Ekonomika výroby vepřového masa - postavení ČR v Evropě” ("Economics of pig meat production - position of CR in Europe", in Czech), Náš chov, Vol. 75, pp. 73 - 78. ISSN 0027-8068.

[9] Cerqua, A. and Pellegrini, G. (2014) "Do subsidies to private capital boost firm's growth? A multiple regression discontinuity design approach”, Journal of Public Economics, Vol. 109, pp. 114-126. ISSN 0047-2727. DOI 10.1016/j.jpubeco.2013.11.005.

[10] Coad, A. and Rao, R. (2008) "Innovation and firm growth in high-tech sectors: A quantile regression approach", Research Policy, Vol. 37, No. 4, pp. 633-648. ISSN 0048-7333. DOI 10.1016/j.respol.2008.01.003. 
[11] Čechura, L. (2009) "Zdroje a limity růstu agrárniho sektoru” (in Czech), Prague, Wolters Kluwer, p. 296, ISBN 978-80-7357-493-2.

[12] Čechura, L. and Hockmann, H. (2010) "Sources of Economical Growth in the Czech Food Processing", Prague Economic Papers, Vol. 2, pp. 169-182. ISSN 2336-730X. DOI 10.18267/j.pep.370.

[13] Čechura L. and Hockmann H. (2011) "Efficiency and Heterogeneity in Czech Food Processing Industry", EAAE 2011 Congress Change and Uncertainty. ETH Zurich.

[14] Čechura L. and Hockmann H. (2017) "Heterogeneity in Production Structures and Efficiency: An Analysis of the Czech Food Processing Industry", Pacific Economic Review, Vol. 22, No. 4, pp. 702-719. ISSN 1468-0106. DOI 10.1111/1468-0106.12217.

[15] Čechura, L. and Malá, Z. (2014) "Technology and Efficincy Comparison of Czech and Slovak Processing Companies", Procedia Economics and Finance, Vol. 12, pp. 93-102. ISSN 2212-5671. DOI 10.1016/S2212-5671(14)00324-4.

[16] Daňková, A. and Bosáková, Z. (2005) "The Competitiveness of the Chosen Processing Branches Slovak Food Industry”, Ekonomický časopis, Vol. 53, No. 4, pp. 415-426. ISSN 0013-3035.

[17] Farrell, M. J. (1957) “The Measurement of Productive Efficiency”, Journal of the Royal Statistical Society, Vol. 120, No. 3, pp. 253-290. ISSN 00359238.

[18] Geroski, P. A. (2005) "Understanding the implications of empirical work on corporate growth rates", Managerial and Decision Economics, Vol. 26, No. 2, pp. 129-138. ISSN 1099-1468. DOI $10.1002 /$ mde. 1207 .

[19] Geroski, P. A., Machin, J. and Walters, C. F. (1997) "Corporate growth and profitability", Journal of Industrial Economics, Vol. 45, No. 2, pp. 171-189. ISSN 1467-6451. DOI 10.1111/1467-6451.00042.

[20] Greene, W. (2005) "Fixed and Random Effects in Stochastic Frontier Models", Journal of Productivity Analysis, Vol. 23, No. 1, pp. 7-32. ISSN 1573-0441. DOI 10.1007/s11123-004-8545-1.

[21] Hadley, D. (2006) "Patterns in technical efficiency and technical change at the farm-level in England and Wales, 1982-2002", Journal of Agricultural Economics, Vol. 57, No. 1, pp. 81-100. ISSN 1477-9552. DOI 10.1111/j.1477-9552.2006.00033.x.

[22] Harris, R., and Trainor, M. (2005) "Capital subsidies and their impact on total factor productivity: firm-level evidence from Northern Ireland", Journal of Regional Science, Vol. 45, No. 1, pp. 49-74. ISSN 1467-9787. DOI 10.1111/j.0022-4146.2005.00364.x.

[23] Jondrow, J., Lovell, C. A. K, Materov, I. S. and Schmidt, P. (1982) "On the estimation of technical inefficiency in the stochastic frontier production function model", Journal of Econometrics, Vol. 19, No. 2, pp. 233-238. ISSN 0304-4076. DOI 10.1016/0304-4076(82)90004-5.

[24] Karagiannis, G. and Sarris, A. (2005) "Measuring and explaining scale efficiency with the parametric approach: The case of Greek tobacco growers", Agricultural Economics, Vol. 33, No. 3, pp. 441-451. ISSN 1574-0862. DOI 10.1111/j.1574-0864.2005.00084.x.

[25] Kumbhakar, S. C. and Lovell, C. A. K. (2000) "Stochastic Frontier Analysis", Cambridge, Cambridge University Press, p. 333, ISBN 0-521-48184-8.

[26] Kumbhakar, S. C. and Lien, G. (2010) "Impact of Subsidies on Farm Productivity and Efficiency". In: Ball V., Fanfani R., Gutierrez L. (eds). "The Economic Impact of Public Support to Agriculture. Studies in Productivity and Efficiency". Springer, New York, p. 348. ISBN 978-1441963840.

[27] Menrad, K. (2004) "Innovations in the food industry in Germany", Research Policy, Vol. 33, No. 6-7, pp. 845-878. ISSN 0048-7333. DOI 10.1016/j.respol.2004.01.012.

[28] Mezera, J. and Špička, J. (2013) "Economic Effects of Investment Support of Adding Value to Food Products", Agris on-line Papers in Economics and Informatics, Vol. 5, No. 1, pp. 39-49. ISSN 1804-1930. 
[29] Mezera, J., Němec, R. and Špička, J. (2014) "Support of strengthening the cooperation and efficiency factors accelerating innovation processes in the food industry", Agricultural Economics-Czech, Vol. 60, No. 7, pp. 295-300. ISSN 0139-570X.

[30] Ministry of Agriculture of Czech Republic (2016) "Panorama of food industry 2016", Ministry of Agriculture of Czech Republic, Prague. ISBN 978-80-7434-387-2.

[31] Minviel, J. J. and Latruffe, L. (2017) "Effect of public subsidies on farm technical efficiency: a meta-analysis of empirical results", Applied Economics, Vol. 49, No. 2, pp. 231-226. ISBN 1466-4283. DOI 10.1080/00036846.2016.1194963.

[32] Mroczek, R. (2013) "Investment, assets of enterprises and productivity of the polish food industry" In: Hradec Economic Days 2013 - International Conference. Hradec Králové, pp. 258-265.

[33] Nivievskyi, O. and von Cramon-Taubadel, S. (2008) "The Determinants of Dairy Farming Competitiveness in Ukraine", $12^{\text {th }}$ EAAE Congress, Gent, Belgium, 27-30 August.

[34] Pechrová, M. and Vlašicová, E. (2013) "Technical Efficiency of Organic and Biodynamic Farms in the Czech Republic", Agris on-line Papers in Economics and Informatics, Vol. 5, No. 4, pp. 143-152. ISSN 1804-1930.

[35] Piesse, J. and Thirtle, C. (2000) “A stochastic frontier approach to firm level efficiency, technological change and productivity during the early transition in Hungary", Journal of Comparative Economics, Vol. 28, No. 3, pp. 473-501. ISSN 0147-5967. DOI 10.1006/jcec.2000.1672.

[36] Rudinskaya, T. (2017) "Heterogeneity and efficiency of food processing companies in the Czech Republic", Agricultural Economics - Czech, Vol. 63, No. 9, pp. 411-420. ISSN 0139-570X. DOI 10.17221/1/2016-AGRICECON.

[37] Skuras, D., Tsekouras, K., Dimara. E. and Tzelepis. D. (2006) “The Effects of Regional Capital Subsidies on Productivity Growth: A Case Study of the Greek Food and Beverage Manufacturing Industry", Journal of Regional Science, Vol. 46, No. 2, pp. 355-381. ISSN 1467-9787. DOI 10.1111/j.0022-4146.2006.00445.x.

[38] Špička, J., Náglová, Z. and Gürtler, M. (2017) "Effects of the investment support in the Czech meat processing industry”, Agricultural Economics- Czech, Vol. 63, No. 8, pp. 356-369. ISSN 0139-570X. DOI 10.17221/367/2015-AGRICECON.

[39] Trnková, G., Malá, Z. and Vasilenko, A. (2012) "Analysis of the Effects of Subsidies on the Economic Behavior of Agricultural Businesses Focusing on Animal Production", Agris on-line Papers in Economics and Informatics, Vol. 4, No. 4, pp. 115-126. ISSN 1804-1930.

[40] Wynarczyk, P. and Thwaites, A. (1997) "The Economic Performance. Survival and Non-Survival of Innovative Small Firms ". In: Oakey. R., \& Mukhtar. S. "New Technology Based Firms in the 1990". London: Paul Chapman.

[41] Zhu, X., Lansink, A. O. (2008) "Technical Efficiency of the Crop Farms Under the Various CAP Reforms: Empirical Studies of Germany, the Netherlands and Sweden." In: $107^{\text {th }}$ EAAE European Association of Agricultural Economists, Sevilla, Spain.

[42] Zhu, X. and Oude Lansink, A. (2010) "Impact of CAP Subsidies on Technical Efficiency of Crop Farms in Germany, the Netherlands and Sweden.", Journal of Agricultural Economics, Vol, 61, No. 3, pp. 545-564. ISSN 1477-9552. DOI 10.1111/j.1477-9552.2010.00254.x. 